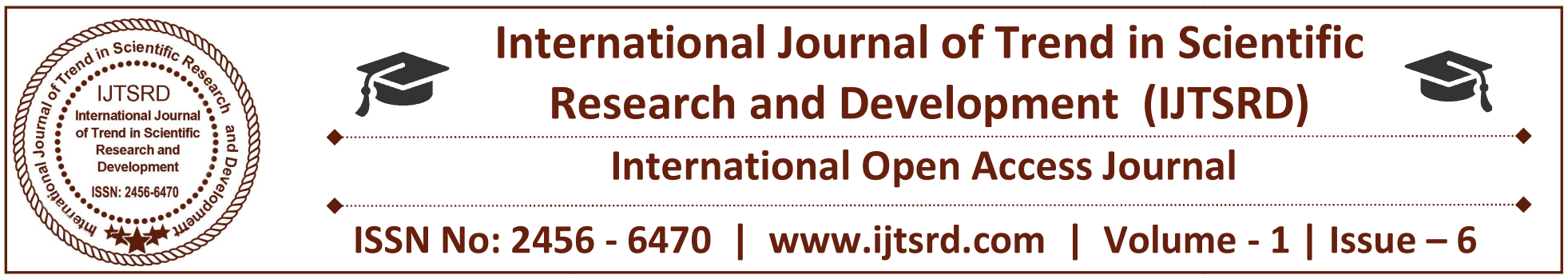

\title{
Implemetation of Kanban
}

\author{
Makarand Prabhakar Lehekar \\ Deogiri Institute of Engineering \& Technology, \\ Aurangabad, India
}

Prof. Mangesh Urne

Deogiri Institute of Engineering \& Technology, Aurangabad, India

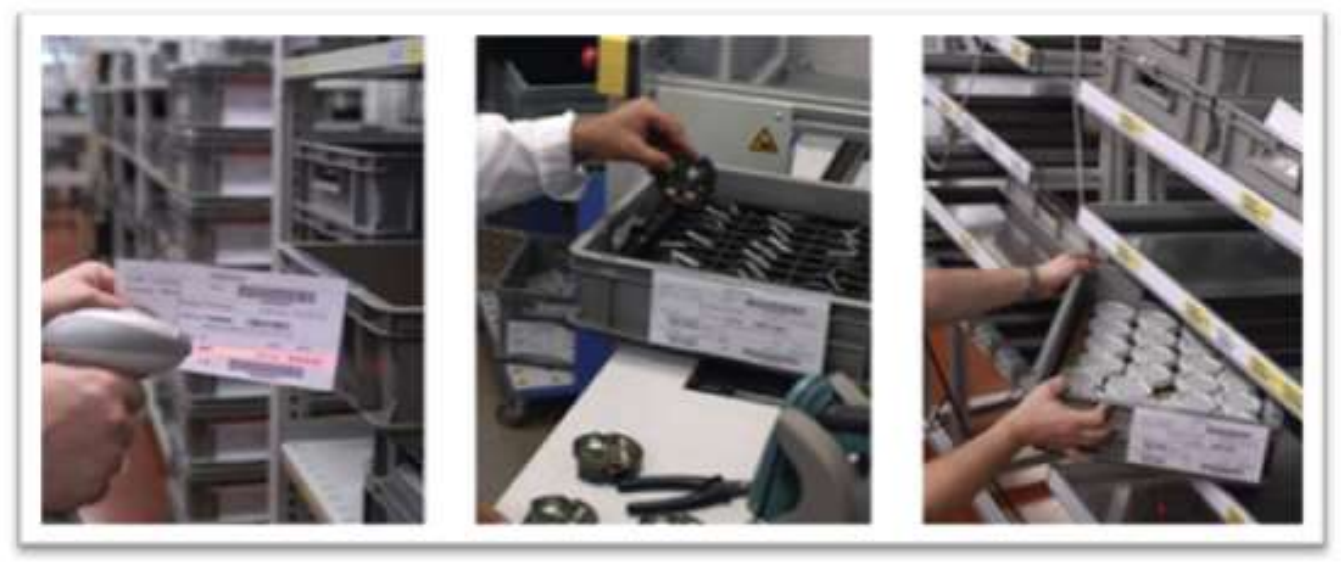

SAP R/3 ERP 6.0

\section{Principle}

Kanban (かんばん(看板) is a scheduling system for lean and just-in-time (JIT) production. Kanban is a system to control the logistical chain from a production point of view. Kanban was developed by Taiichi Ohno, at Toyota, to find a system to improve and maintain a high level of production. Kanban is one method through which JIT is achieved.

Kanban became an effective tool in support of running a production system as a whole, and it proved to be an excellent way for promoting improvement. Problem areas were highlighted by reducing the number of kanban in circulation.

\subsection{History}

$>$ Developed by Toyota in year 1950s. (Kanban is a Japanise word \& means Label)

For the following reasons:

1. Overproduction

2. Insufficient Productivity - Avoiding waste

3. Lack of raw material \& space

4. Complexity of central production control
Companywide implementation in Toyota in late 1960s

$>$ In Europe the Kanban is used in early 1990s

$>$ In India the Kanban is used in early 1990s

\subsection{Purpose}

Kanban causes a pulling of material from a downstream position to an upstream position within the production process. This means, the upstream position only supplies the downstream position with parts if they demand them. The demand of parts will be done by the Kanban (jap. for label). The Kanbancard contains all necessary information for the material-flow. Kanban-material buffers between producer and consumer are limited upwards. This cap of the coverage will be achieved by a limited number of Kanban-cards, which are circulating between upand downstream position. Therefore the usage of a Kanban system counteracts the main type of waste "overproduction". 
Kanban aligns inventory levels with actual consumption; a signal is sent to produce and deliver a new shipment when material is consumed. These signals are tracked through the replenishment cycle, bringing visibility to both the supplier and the buyer.

Kanban uses the rate of demand to control the rate of production, passing demand from the end customer up through the chain of customer-store processes.

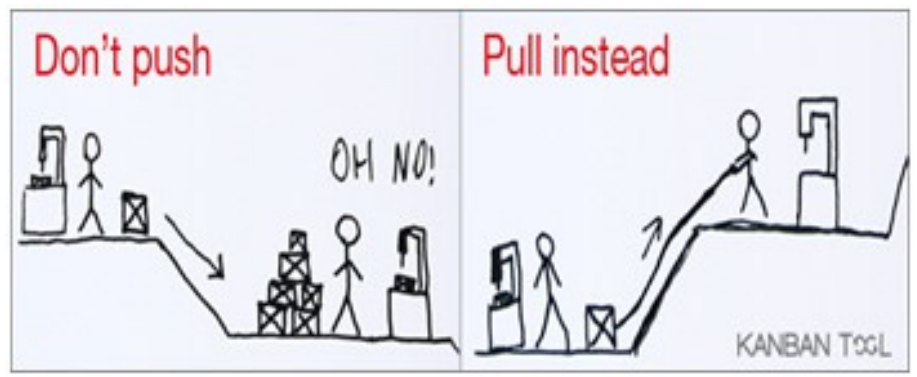

1.3 Currently there exist four different Kanbanmethods:

Production Kanban

Stock transfer Kanban (from central to decentral stock and also from decentral to decentral stock)

Supplier Kanban with external supplier's

NEW: Supplier Kanban with the CONSUMER's or CONSUMER-supply with Kanban (Topic of this manual)

\subsubsection{Supply with Kanban (Supplier-Kanban)}

Procedure

The consumer withdraws parts out of a Kanban bin.

As soon as the parts are completely consumed, the Kanban-Card should be scanned EMPTY and destroyed afterwards.

Caused by this EMPTY-Scan a new Kanban-replenishment-purchase order (Kanban-PO) for the quantity of this bin will be created.

A cyclic job (ZMZKAN09) at the consumer checks the data of all KanbanPO's. If all data are OK the status of the Kanban bin will be set to PROCESS "Container in process" and the EOI order transfer will be started.

The supplier get's a new Sales order created by EOI. This Sales-order obtains the delivery priority "88" which identifies them as special Kanban Sales orders (Kanban SO).

A cyclic job at Supplier checks the availability in the Supplier-Kanban stock and if the material is available, the Kanban-SO will be released and confirmed automatically.

Another cyclic job creates the delivery note and prints the Kanban-Card directly in -shipment dept. at Supplier automatically.

After packing and labeling the goods, the "goods issue" will be posted in Supplier and the bin status at the consumer will be set to TRANSP "Container in transport". The goods will be transported to the Consumer.

After arriving at the Consumer the goods will be transported to its shelf in Consumer-production and the worker does the FULL-Scan on the attached Kanban-Card. MIGO will be done in the background automatically.
Bin Status

6111

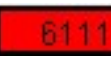

6111

6111

6111

6111

6111 


\section{Requirements}

The following requirements are necessary for the conversion of a material-number at CONSUMERKanban. Each of them will be described in detail:

Appropriate material-numbers.

Supermarket-shelves which comply with the standard.

Existing Kanban-Terminals with SAP-access.

> Material-number must be already set up in the Kanban-stock of the supplier.

\subsection{Material-Numbers}

An appropriate material-number for CONSUMERKanban should have a consumption of minimum the quantity of one Kanban-bin per month or more. This consumption has to be regular, which means min. once a month.

The calculation of the number of bins, considering consumption, filling-quantity, replacement-time and safety-time, should be done with this suggested Excelsheet.

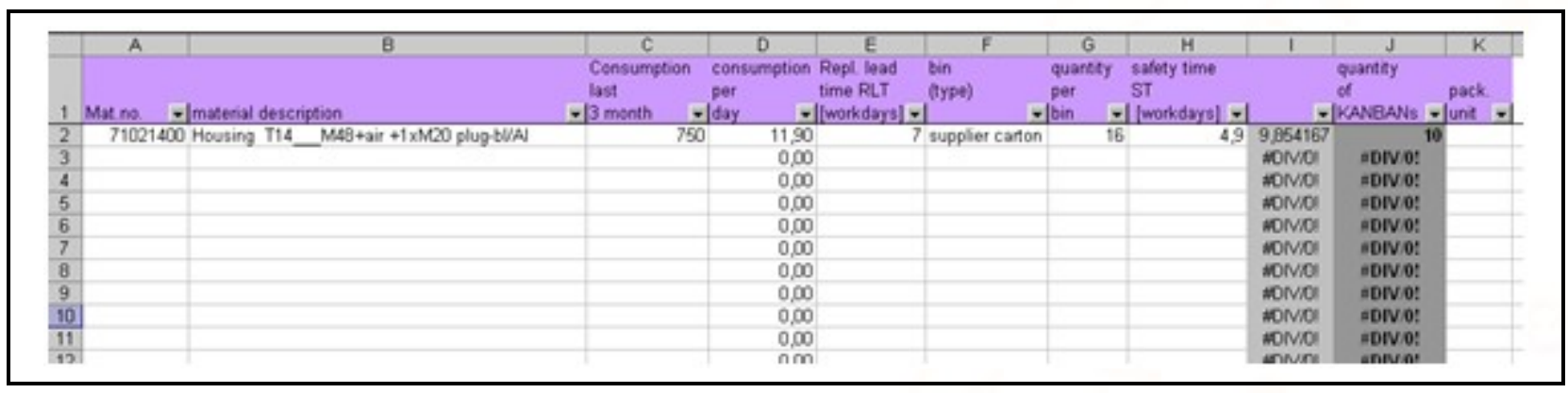

In this sheet can be filled in all material-numbers with their shorttext, material -type and consumptions. Afterwards the following fields have to be filled in for the calculation of the number of bins:

Replacement time or replenishment lead time $(\mathrm{RLT}=$ time between Empty- and full-scan)

\section{Kanban-bin}

Quantity per bin

$>$ Safety time (min. half RLT)
On the basis of this data, the needed number of bins/cards which have to be circulated, will be calculated automatically (Column "Cards rounded"). The calculation will be done with the following formula:

$$
\text { Number of Kanban cards }=\frac{(\varnothing \text { Consumption } / \mathrm{WD} \times \mathrm{RLT})+(\mathrm{ST} \times \varnothing \text { Consumption } / \mathrm{WD})}{\text { Quantity } / \mathrm{bin}}+1_{1)}
$$

RLT: Replacement time or replenishment lead time in WDs (time between Empty- and full-scan) ST: Safety time in WDs

WD: Workday

1) Container from which currently the parts will be withdrawn (Container in use!)

\subsection{Supermarket}

A Kanban-storage (also called Supermarket-shelve) should be built, as in two pager No. HA 9 explaine. 


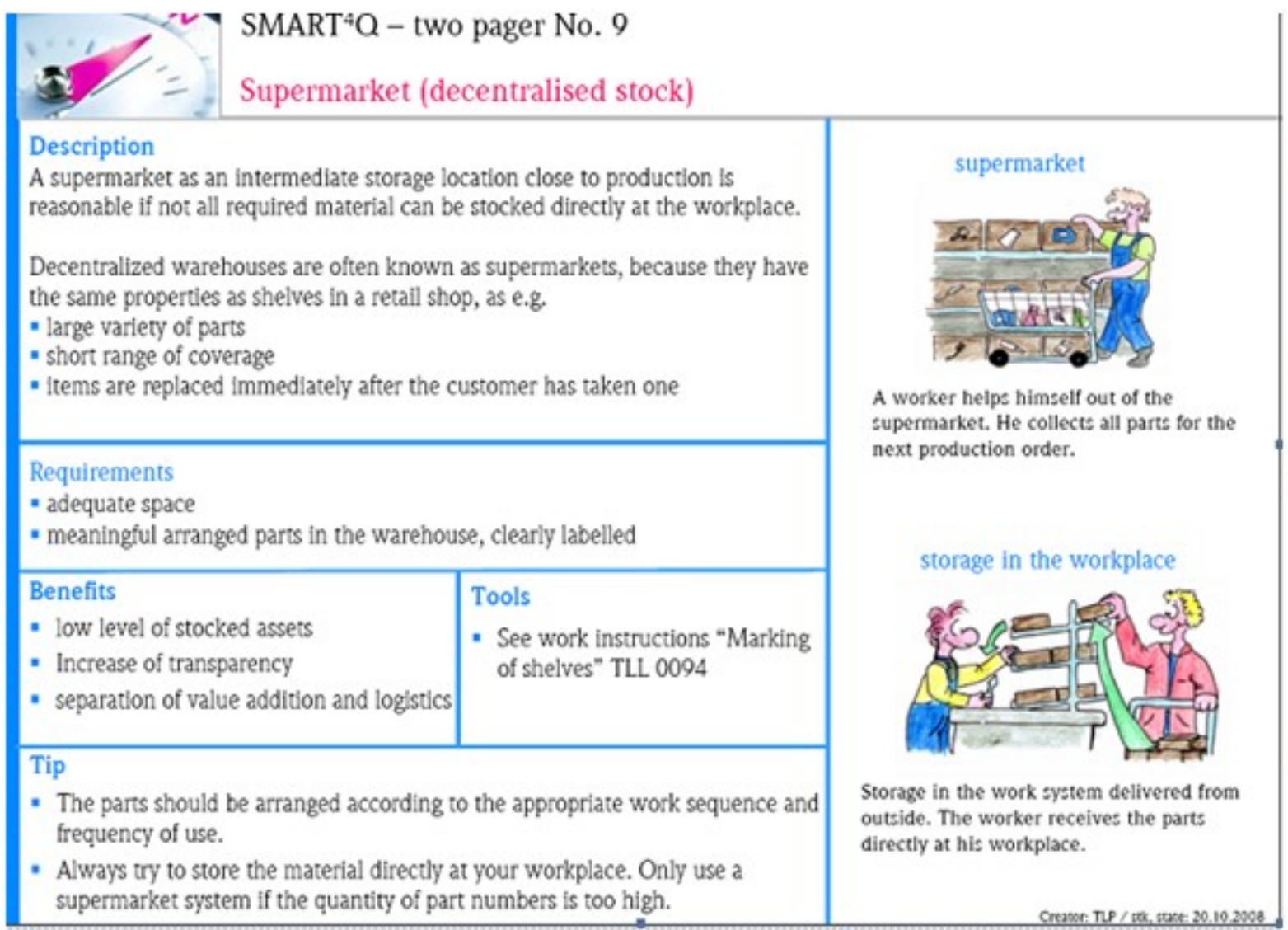

\subsection{Kanban-Terminal}

For an effecient handling of the Kanban-process a "Kanban-terminal" in close proximity to the Kanban-storage is important. This terminal constists of a computer with SAP-access, a large screen (min. 19 inches diagonal) and a wireless barcode-scanner. This "Kanban-terminal" should meet two requirements. On the one hand, there should be done the "Empty- and the Full-scans" of the Kanban-cards from the assigned Kanban-storage, on the other hand, it serves the purpose of visualization of all the Kanban controlcycles of this Kanban-storage (Kanban-board e.g. in order of their urgency).

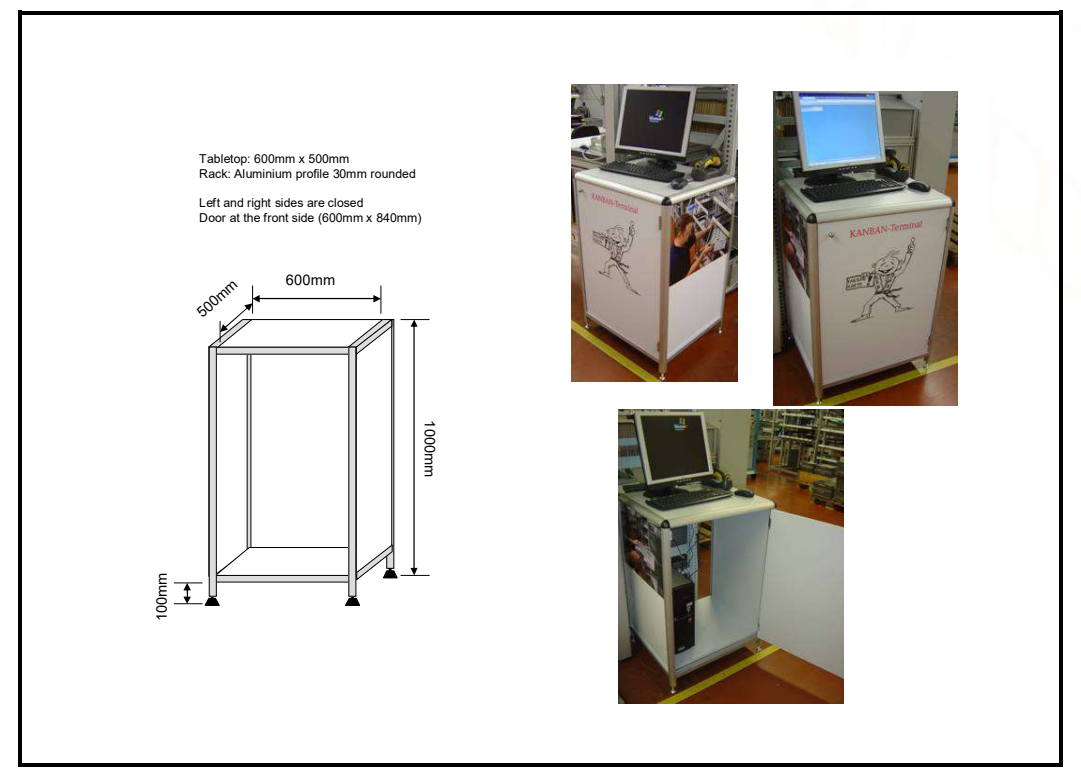




\section{Setup}

\subsection{Supply area}

A supply area in SAP is always allocated to a storage location and specifies where Kanban-material must be delivered. A supply area is always a subarea of one decentral stock area.

A supply area is defined in the Kanban-Customizing of SAP and allocated to the following objects:

\section{One plant}

One storage location

Person in charge or Responsible (normally the MRP-controller in SAP)

The posting of any material movements will be done on the allocated storage location. Multiple supply areas can be created in one storage location, but one supply area can't be allocated to different storage locations.

If one material is used in different supply areas which are allocated to the same storage location, the view of the stock overview (MMBE) shows always a total sum of all different supply areas.

As a matter of principal, supply areas should be centrally administrated (by the Kanban-experts)

\subsubsection{Creation of supply areas in SAP with PK05}

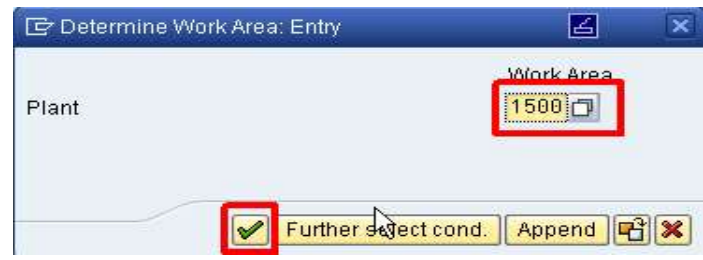

\begin{tabular}{|c|c|c|c|}
\hline \multicolumn{4}{|c|}{ Change View "Supply Area": Overview } \\
\hline$\infty$ & New Entries & 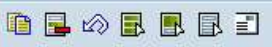 & \\
\hline PInt & PrSuppArea & Supply area descr. & 四 \\
\hline 1500 & G0018 & Test supply area klw en & $\Delta$ \\
\hline 1500 & G007A & Test supply area for $\mathrm{G} 007 \mathrm{ak}$ & 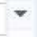 \\
\hline 1500 & G0998 & Test supply area for G007 ak & \\
\hline 1500 & HSG & & \\
\hline 1580 & LIQUI & I & \\
\hline
\end{tabular}

\begin{tabular}{|c|c|c|}
\hline \multicolumn{3}{|c|}{ New Entries: Details of Added Entries } \\
\hline \multicolumn{3}{|c|}{ 的圆圆国韭 } \\
\hline Plant & 15000 & Endress+Hauser (USA) \\
\hline Supply Area & 60038 & Supply area stor. loc. G003 Levelflex \\
\hline Stor. Location & 6003 & FN06A LEVEL FLEX \\
\hline Responsible & GK1 & Gnwd KB-1 \\
\hline Unloading Point & & \\
\hline
\end{tabular}

\section{PK05}

Select plant an click ENTER

Click "New Entries"

Fill in the necessary data.

回 Save the new supply area. 


\subsubsection{Change}

\section{Change View "Supply Area": Overview}

为 NewEntries 说圆圆圆圆品

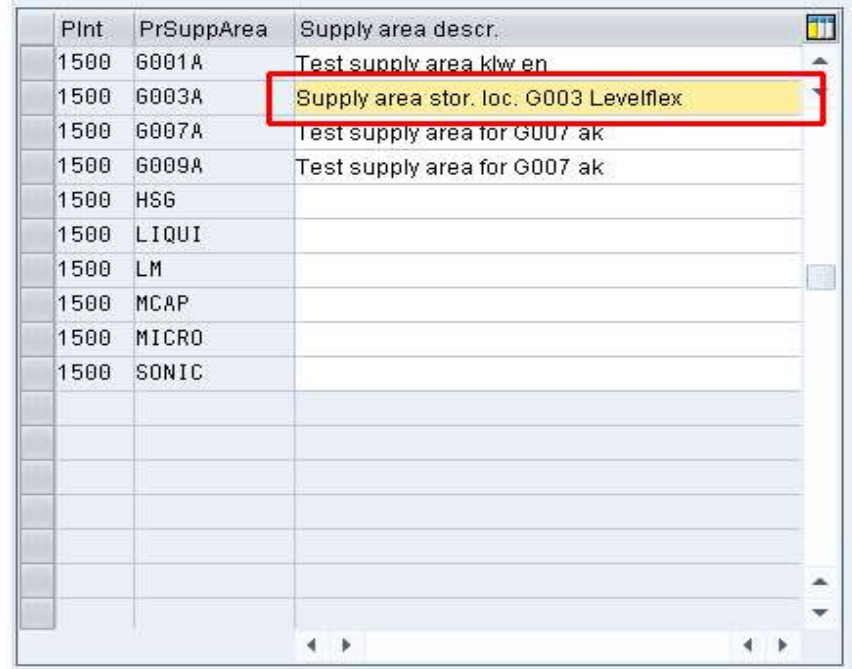

影 Position... Entry 6 of 15

\section{PK05}

Double click the row which should be changed. Then do the changes and

回 Save changes.

\subsubsection{Delete}

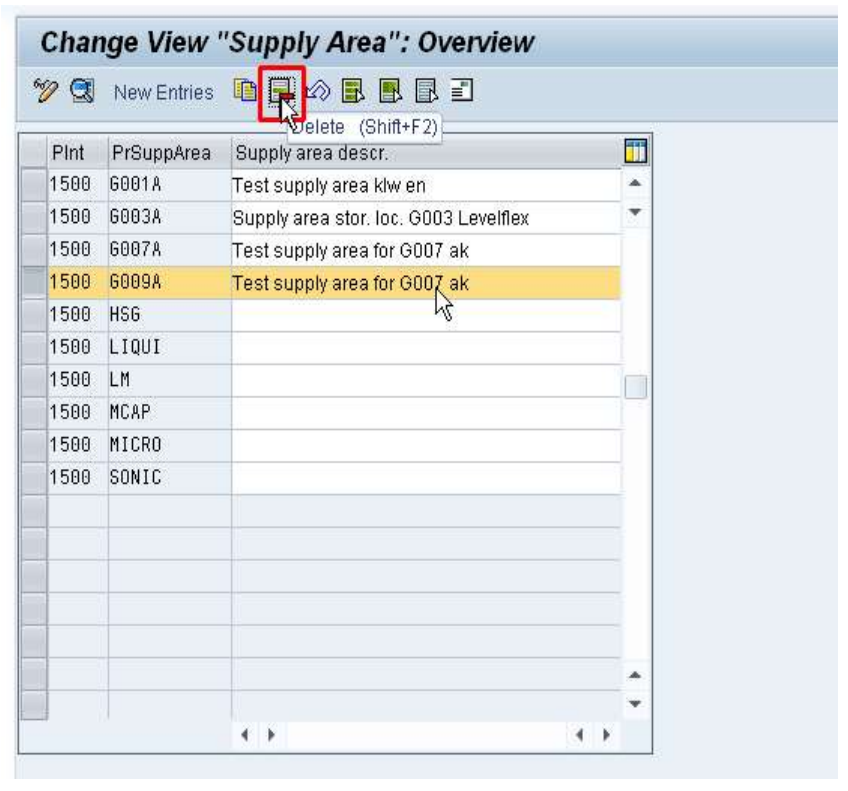

\subsection{Control cycle}

\subsubsection{Creation of control cycle (PKMC)}

\section{PK05}

Mark/highlight the row which should be deleted. Then click "delete" and

回 Save changes.

Supply areas can only be deleted if there are nomore any controlcycles allocated to this supply area.

Delete controlcycles first. 


\section{CONSUMER-Supply with Kanban (CONSUMIER Supplier-Kanban)}

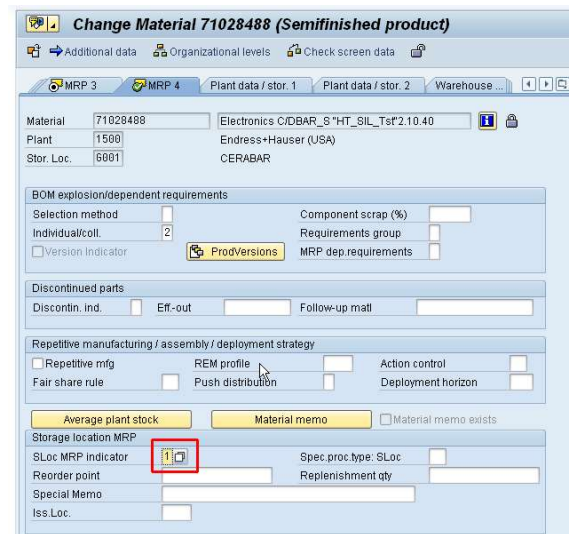

- Stor. Loc. MRP indicator " 1 " in MM02 / MRP4 for the related storage location must be set before starting the creation, otherwise a new controlcycle can't be created. After creation of the controlcycle this field must be deleted again!

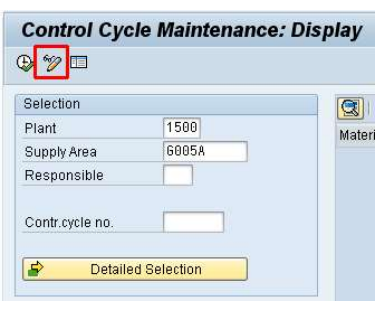

Start PKMC and fill in "Plant" and "Supply area" then press the button to change from "Display" to "Change" mode.

In "Change" - mode there's a button $\square$ to create a new controlcycle.
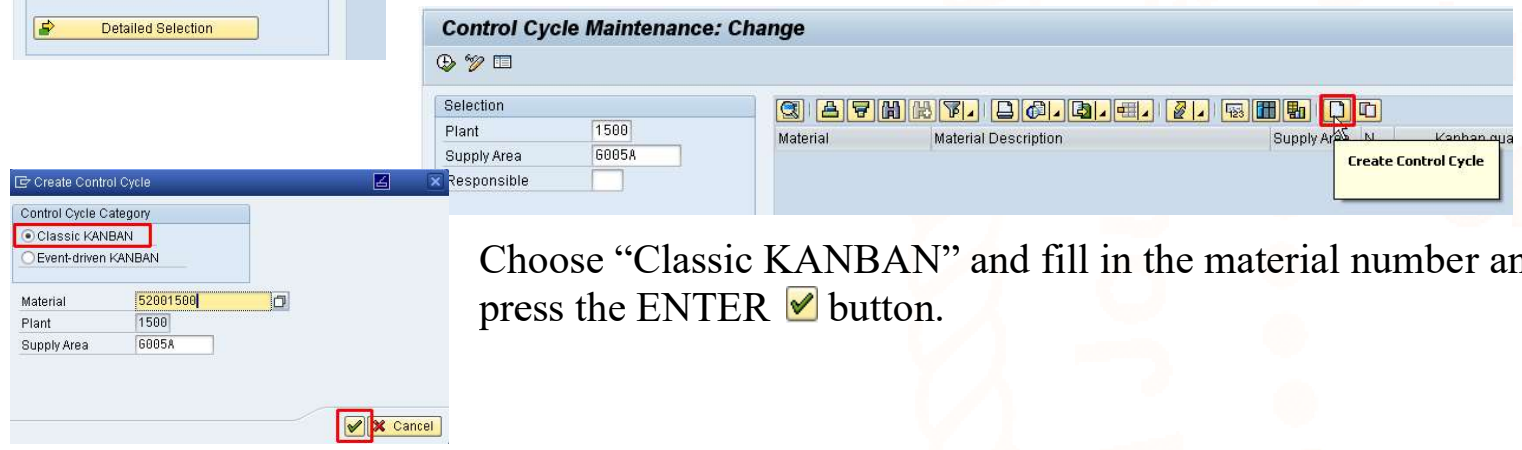

Choose "Classic KANBAN" and fill in the material number and press the ENTER $\unrhd$ button.

Fill in the necessary information: No. of Kanbans, Quantity per bin and choose a container part-no (Only used for printing the container description onto the KanbanCard)

The storing position should only be used if there's more than one supply area on one storage location. Otherwise this information has to be maintained in material master.

For "CONSUMER-supply with Kanban" the

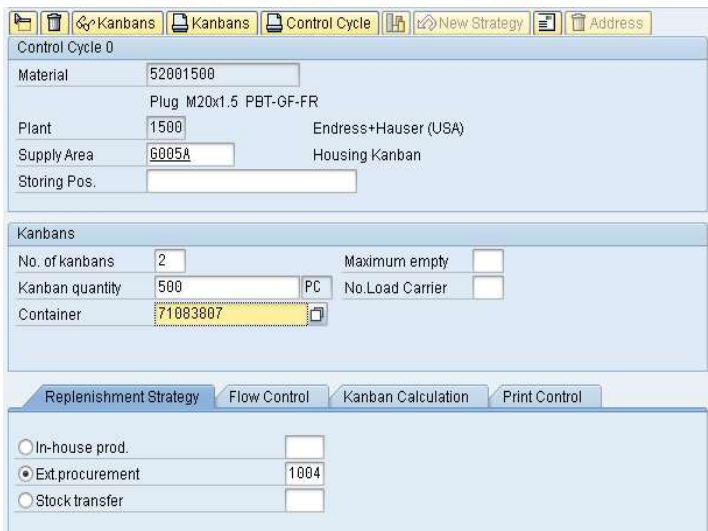
only allowed strategy is "1004". Then hit ENTER

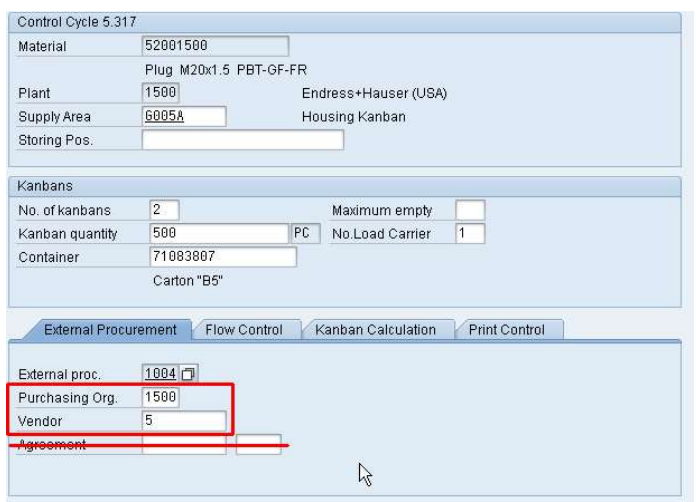

Fill in the necessary information: Purchasing Org. and Vendor-no.

The field Agreement isn't necessary for strategy 1004 ! 


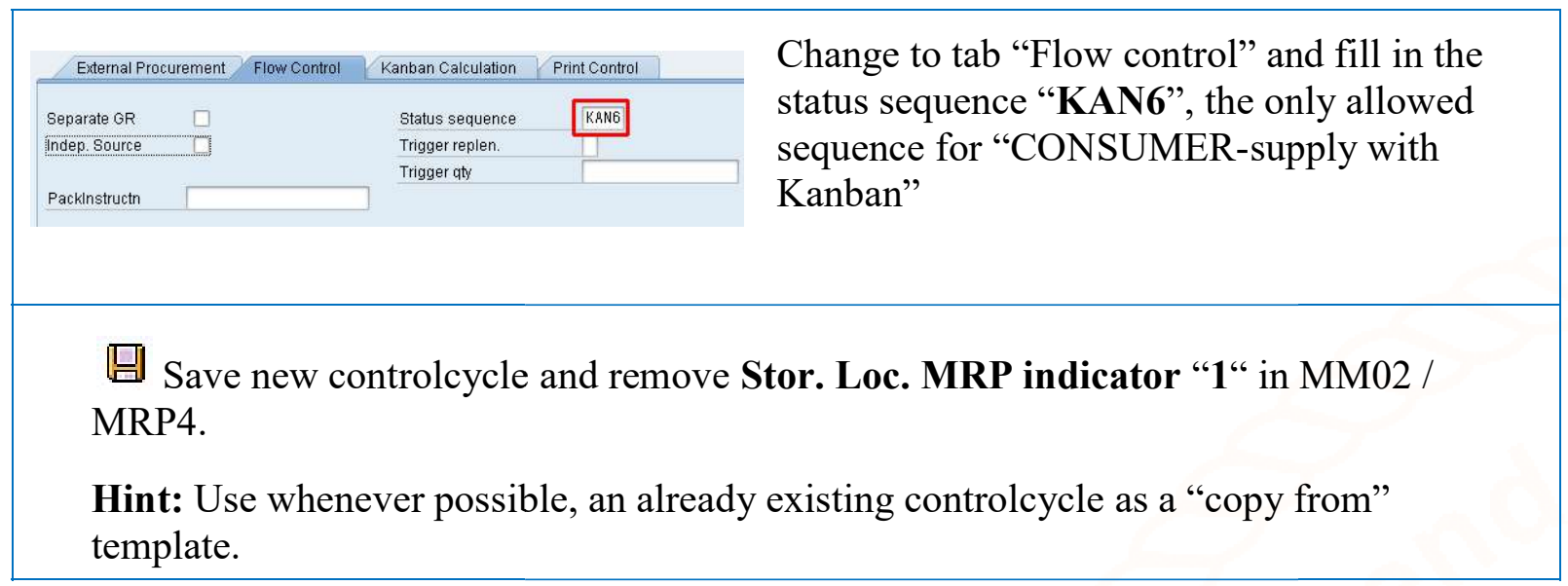

\subsubsection{Creation with template (PKMC)}

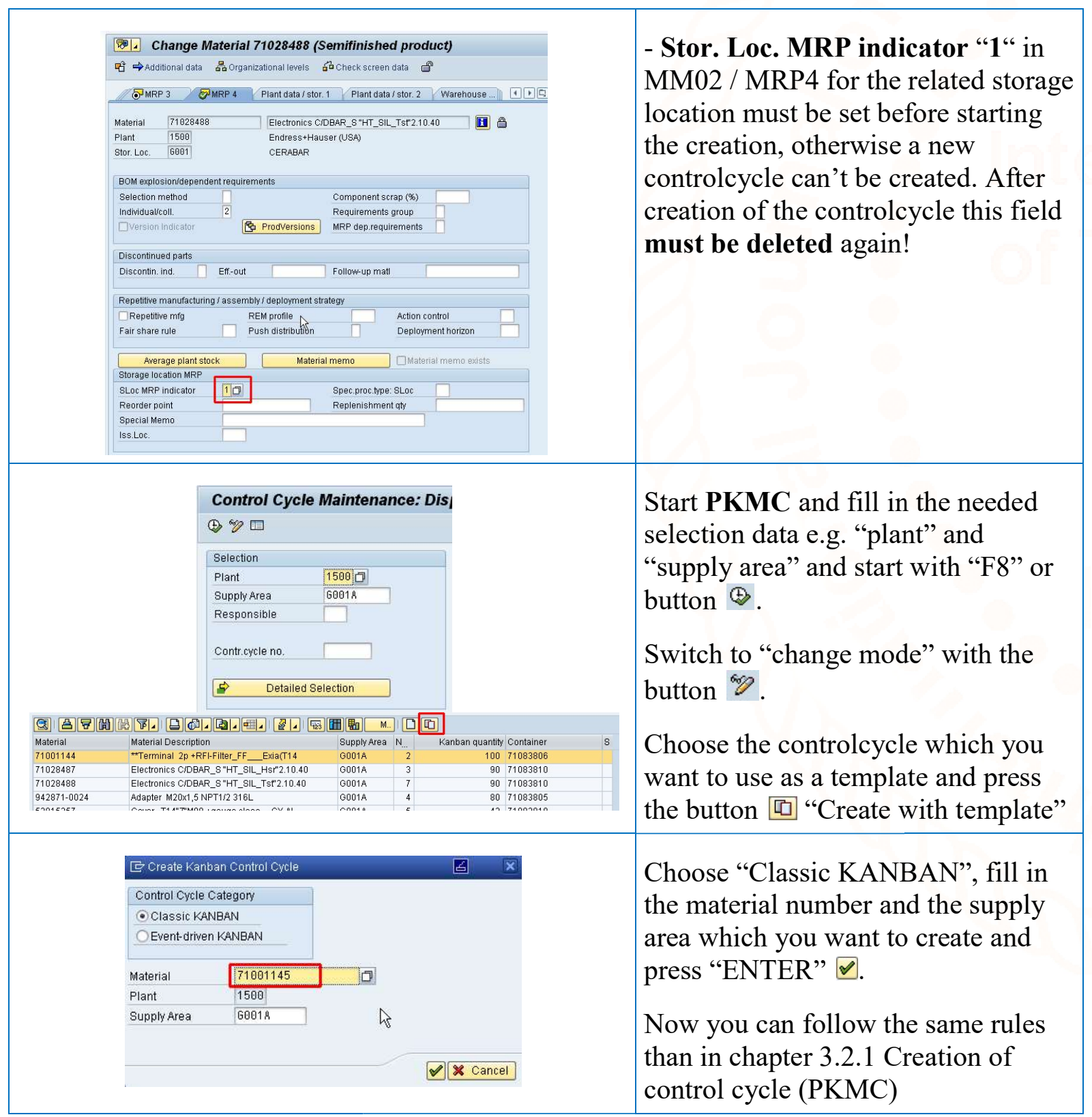


回 Save new controlcycle and remove Stor. Loc. MRP indicator "1" in MM02 / MRP4.

\subsubsection{Change controlcycle (PKMC)}

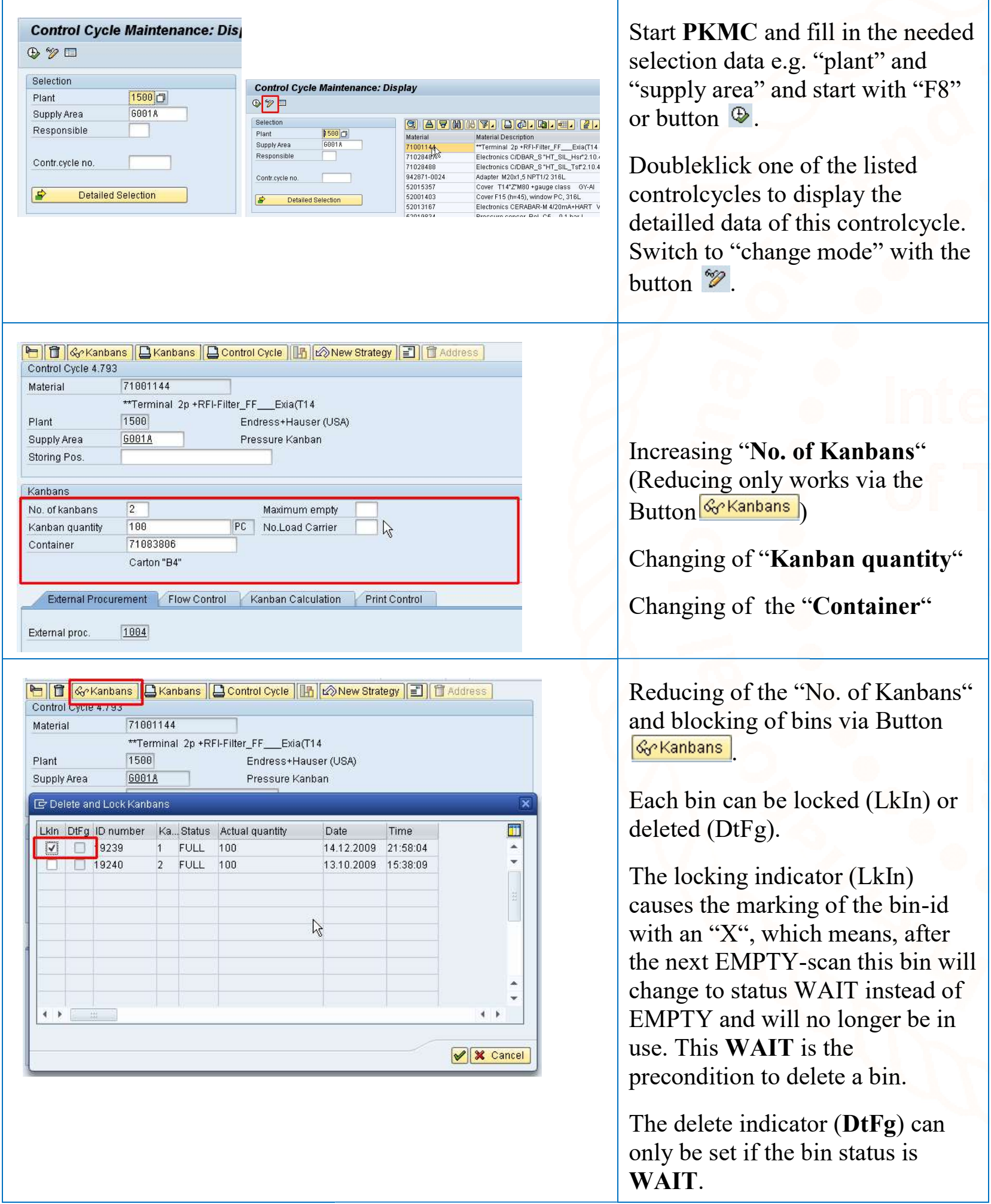




\begin{tabular}{|l|l|}
\hline $\begin{array}{l}\text { [i. Information } \\
\begin{array}{l}\text { No.of kanbans not equalto control cycle data] } \\
\text { data be changed }\end{array}\end{array}$ & $\begin{array}{l}\text { After setting the delete indicator } \\
\text { (DtFg) the "No. of Kanbans".will } \\
\text { be adjusted automatically. }\end{array}$ \\
\hline 回 & Save changes. \\
\hline
\end{tabular}

\subsubsection{Deletion of control cycle (PKMC)}

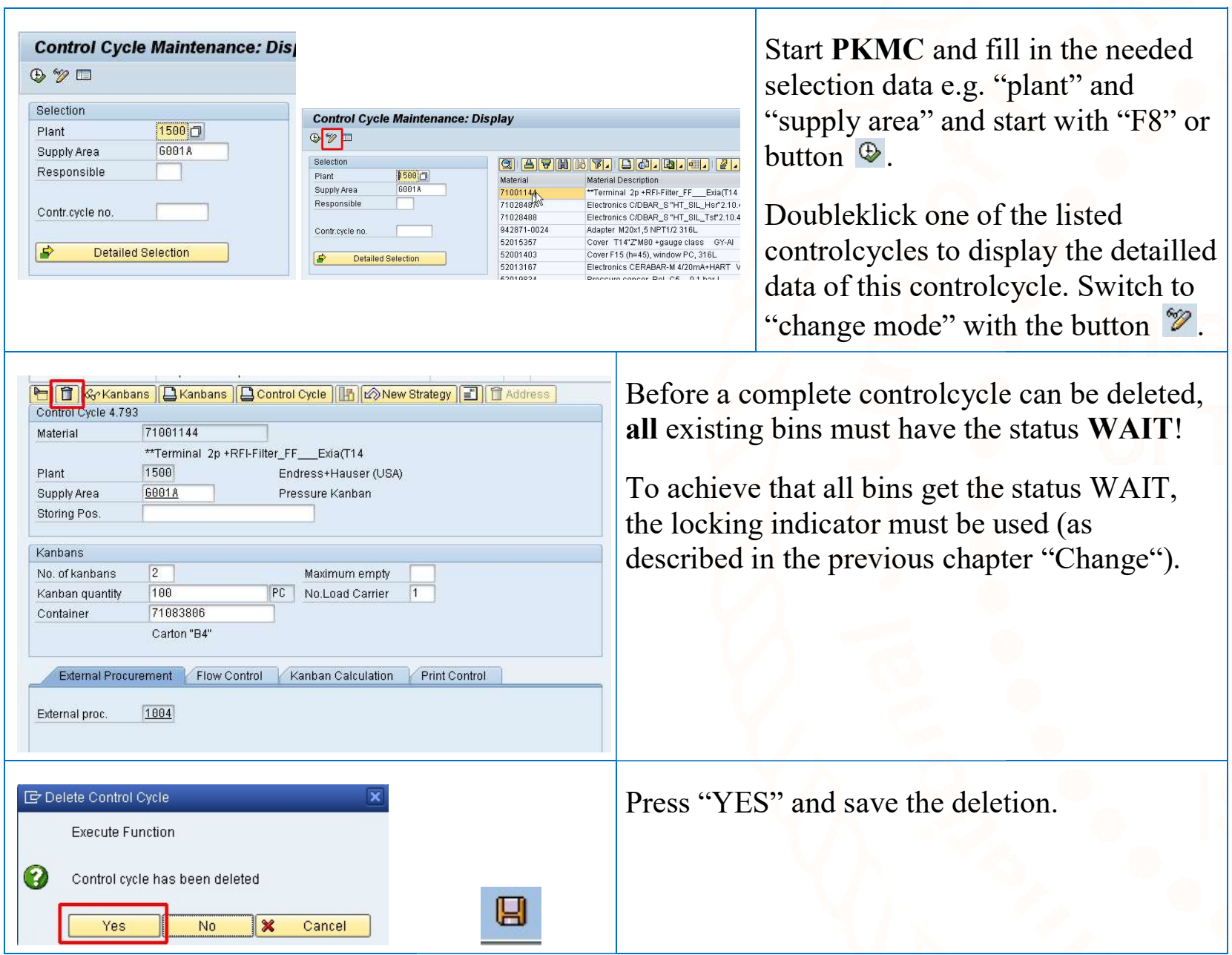


International Journal of Trend in Scientific Research and Development (IJTSRD) ISSN: 2456-6470

\subsection{Material Master Data}

\section{CONSUMIER-Supply with Kanban (CONSUMER Supplier-Kanban)}

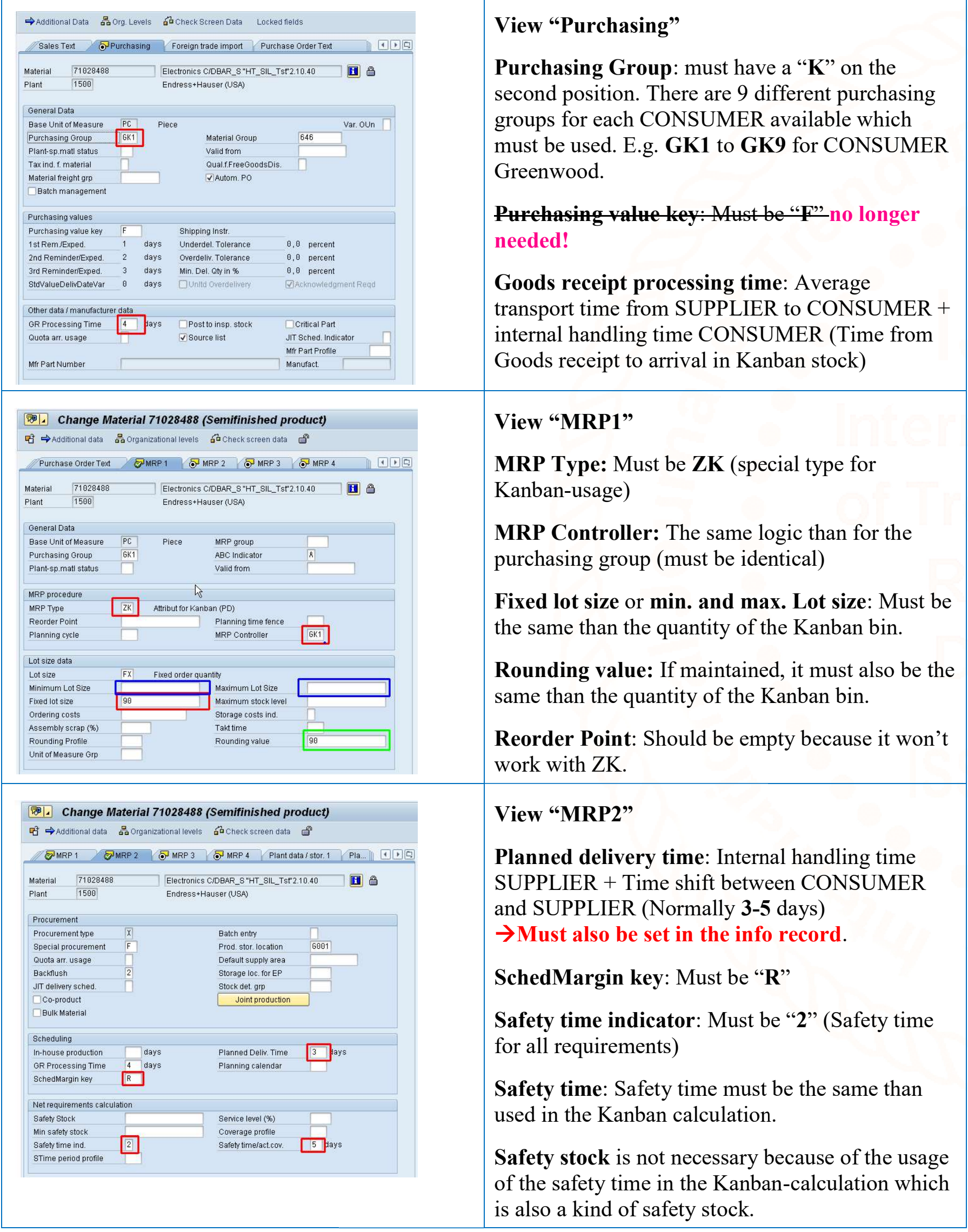




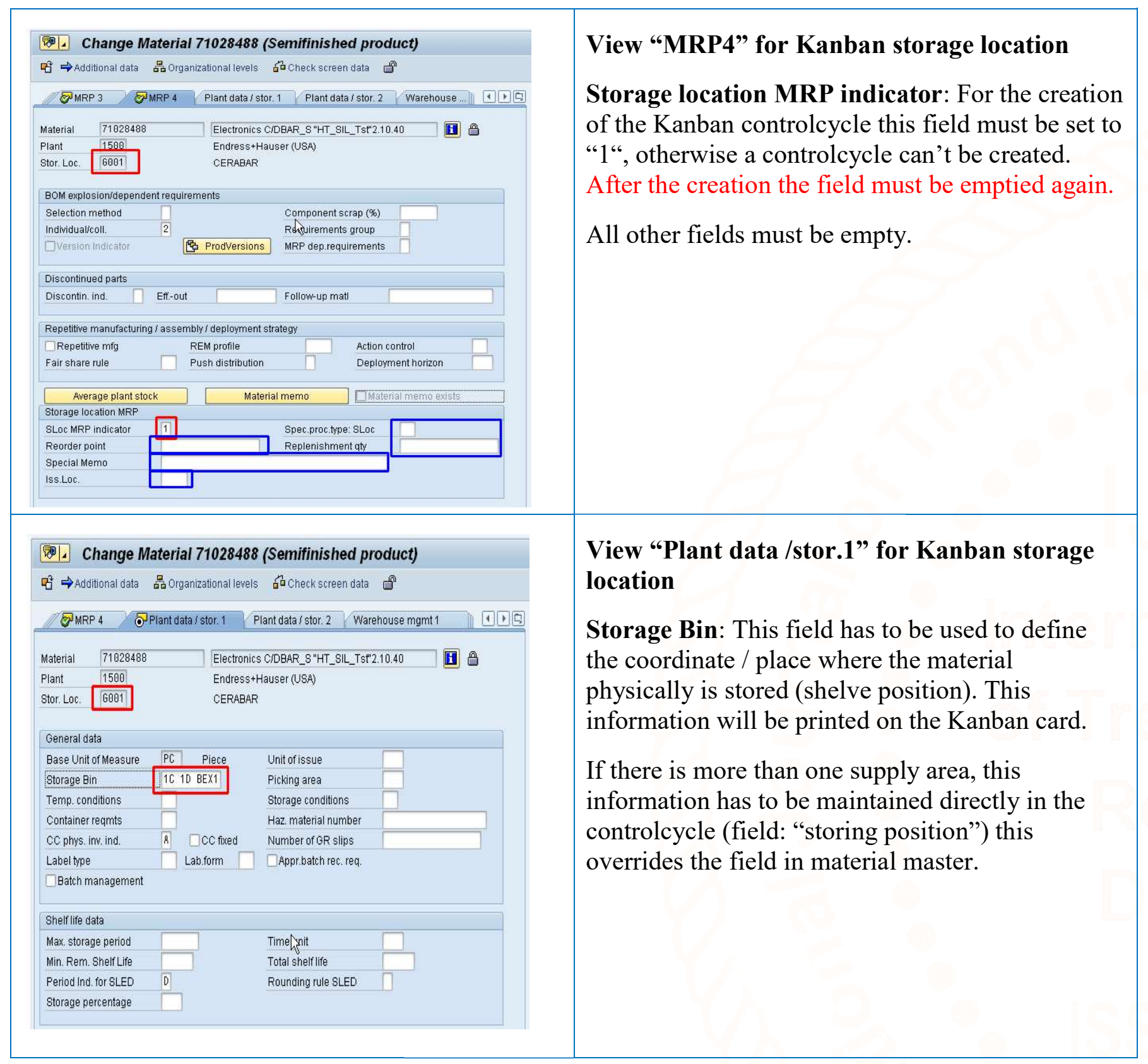




\subsection{Info record / Source list}

\section{CONSUMER-Supply with Kanban (CONSUMER}

\section{Supplier-Kanban)}

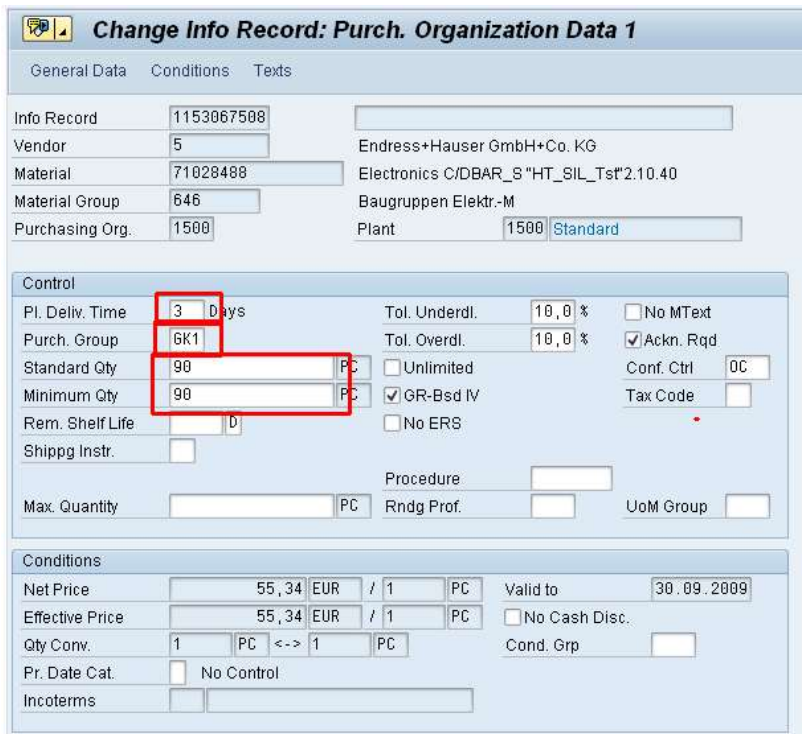

[. Maintain Source List: Overview Screen

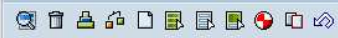

Material 71028488 Electronics CIDBAR_8 "HT_SIL_TSt"2.10.40

Plant 1500 Endress+Hauser (USA)

Source List Records

Valid from valid to vendor POrg PPI OUn Agmt Item Eix BlK MRP MRP Area

01. $07.200631 .12 .99995 \quad 1500$
View "Purch. Organization Data 1"

Planned delivery time: Internal handling time SUPPLIER + Time shift between CONSUMER and SUPPLIER (Normally 3-5 days).

Purch. Group: Same like in Material master

Standard quantity: Must be the same like the quantity of the Kanban bin.

Minimum quantity: Must be the same like the quantity of the Kanban bin.

\section{Source list}

Fixed source of supply: Must be checked

Usage in MRP: Must be "1" 


\section{Startup}

\subsection{Preliminaries}

$>$ Controlcycle is created

Material master data are maintained

$>$ Info record and Source list are maintained

$>$ Supermarket (shelve) is set up and the storage compartment is clearly labeled (coordinate as printed on the Kanban card)

For a smooth transition to a Kanban stock it is necessary to repack the existing stock inventory into the new Kanban bins (same quantity and size). If necessary the remainding inventory from Central stock has to be transfered to the Kanban-storage. For the transition into a Kanban stock we have to create so called "Transition Kanban cards"which can't be done via SAP!

\subsection{Creation of transition cards}

For the creation of these "transition cards" this little Excel tool ("Manual_KANBAN_card.xlt") can be used.

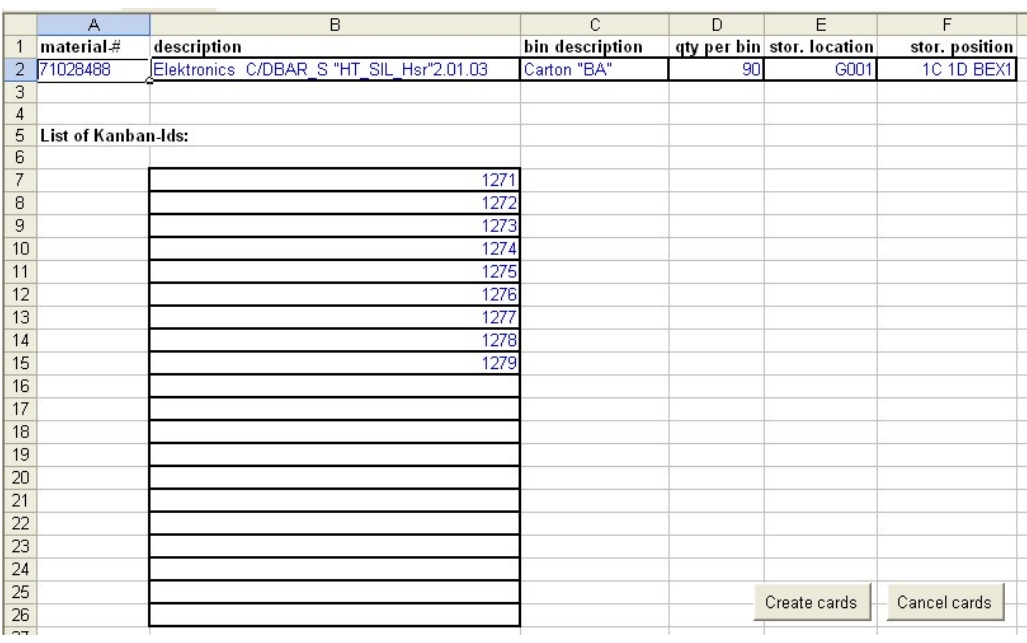

Please fill in the information in line 2 which should appear on the card, then fill in the list of Kanban-IDs of the bins which should get such a initial "transition card".

You can get the necessary information out of SAP-transaction PK18 "Evaluation of Kanban controlcycles"

Max. 20 cards can be created in 1 turn.

Then click the Button create cards.

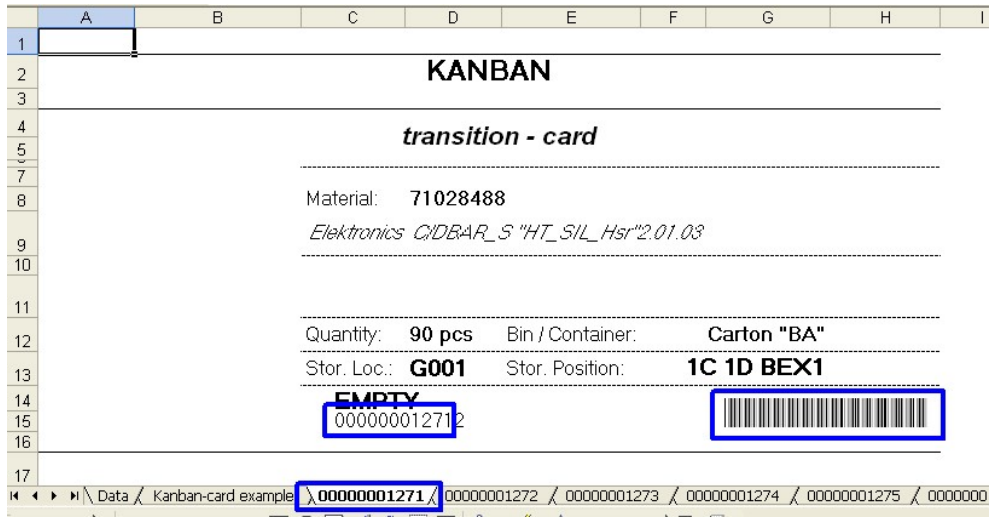

For each Kanban-ID a separate sheet with a Kanban-card will be created.

These cards can be printed out to label the Kanban bins and the existing barcode can be used for the first EMPTY-scan to start replenishment.

After the printout of the cards the sheets with these cards can be deleted with the button cancelcards on the sheet "data".

\section{Please note:}

If the existing stock is higher than the calculated capacity of the new Kanban controlcycle, the leftover has to be used up first (without using Kanban cards).

If the new Kanban controlcycle has more bins than the current stock is covering, the rest of the cards should be 


\section{Operating}

\subsection{Kanban-board}

\subsubsection{Demand source overview}

The "Demand source overview" will be started with the SAP-transaction "PK13N" or using the KanbanCockpit transaction "ZKanban".

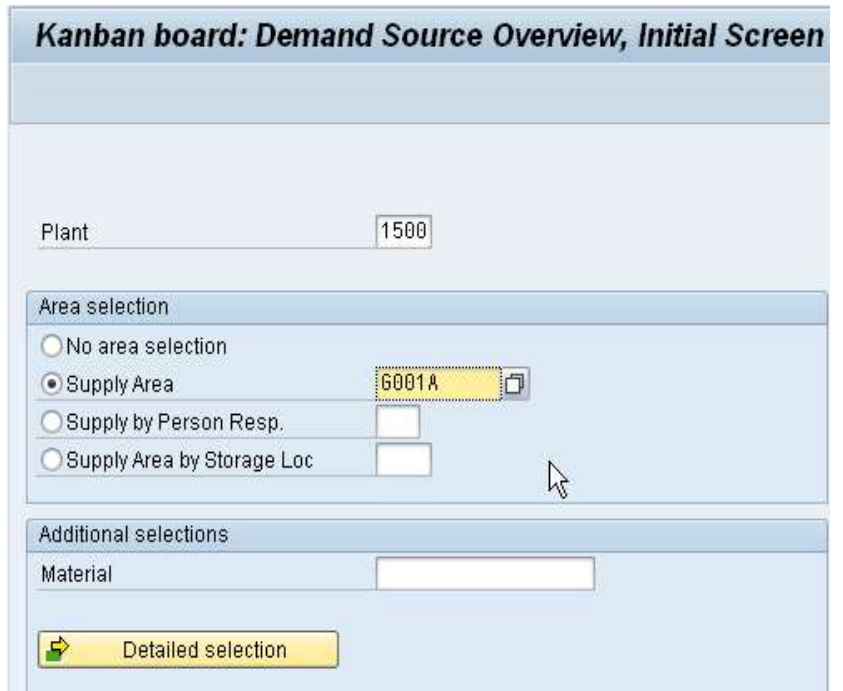

In the initial screen the selection could be done by Supply area, by Responsible for Supply area (Each supply area is allocated to a responsible MRPcotroller (xKx) see chapter 3.1.1) and also by Supply areas by a storage location. With this selection, all Kanban-parts of the chosen storage location will be listed.

With the field "material" a single part-number can be selected and all controlcycles of this part-number will be listed.

With "Detailed selection" more detailed delimitations are possible.

\subsubsection{Setup of Kanban-board}

Change the bin/Kanban display:

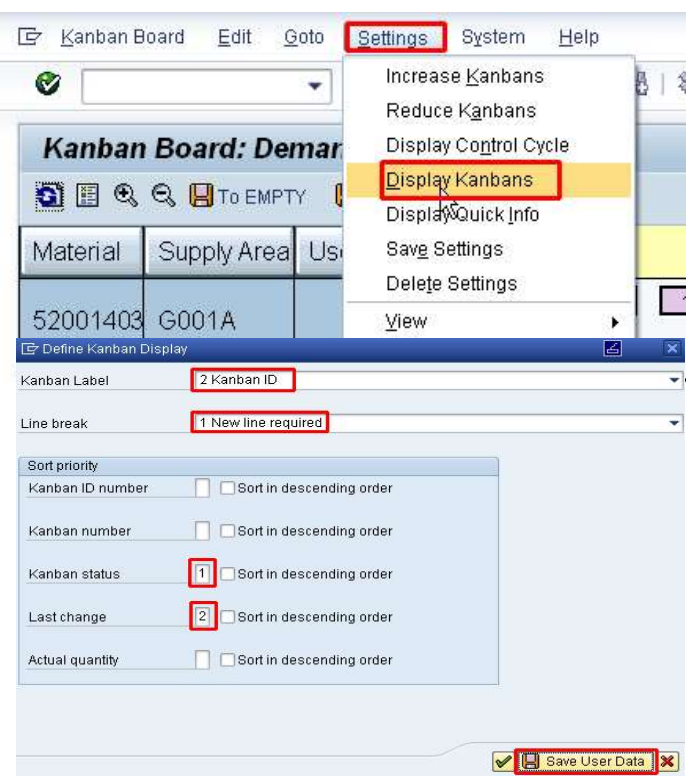

To change the bin/Kanban display use menu "Settings" and choose "Display Kanbans".

SUPPLIER standard setup:

Bins are horizontally sorted

1. By status (ascending)

2. By last change (ascending)

These adjustments have been proven as reliable to trace back possible troubles.

Don’t forget to "Save” (佪 Save User Data) the changes. 
Change the display of the columns:

\begin{tabular}{|c|c|c|c|c|c|c|}
\hline E Kanban $\mathrm{B}$ & pard Endit & soto & Settings & System & Help & \\
\hline 8 & & - & $\begin{array}{l}\text { Increa } \\
\text { Reduo }\end{array}$ & $\begin{array}{l}\text { se Kanbans } \\
\text { Kanbans }\end{array}$ & & 8 \\
\hline Kanban & Board: Den & mar & Displa & KControl Cycle & & \\
\hline 정 $\oplus$ & $\Theta$ 回To EMPT & Y & $\begin{array}{l}\text { Displa } \\
\text { Displa }\end{array}$ & $\begin{array}{l}\text { Kanbans } \\
\text { y Quick Info }\end{array}$ & & \\
\hline Material & Supply Area & US & Save & Bettings & & \\
\hline & & & Delete & Settings & & \\
\hline 52001403 & G001A & & view & & - & \\
\hline & & & & 15800 & & \\
\hline 71001142 & G001A & & & 15847 & 15848 & \\
\hline
\end{tabular}
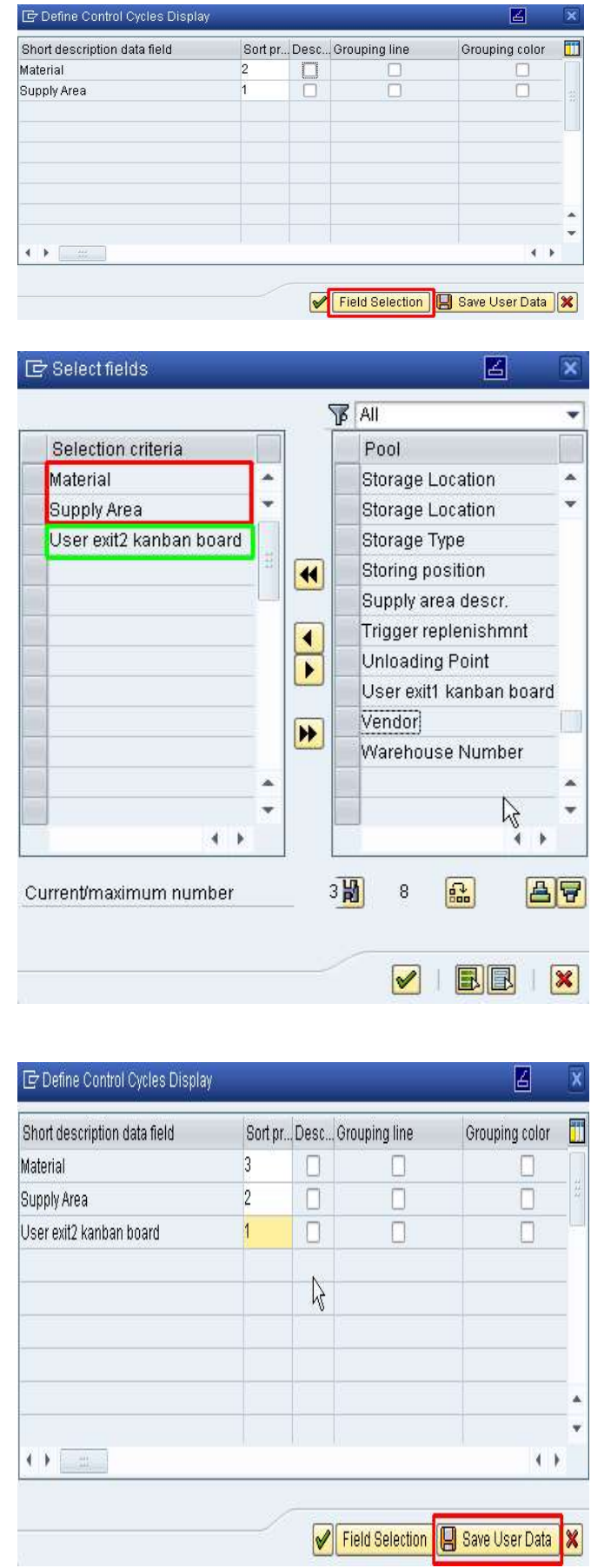

To change the column display use menu "Settings" and choose "Display controlcycles".

Use the button "Field selection" to replace the fields which should be displayed.

There has been programmed a special field to display the urgency of the controlcycles. This field is named "User-exit2".

This urgency is defined as a ratio of "total number of bins" divided by the "number of empty bins". (e.g. total are 11 bins and 6 bins are empty, so the ratio is 1.83 )

The most urgent ratio is $\mathbf{1 . 0}$, which means all bins are empty.

This field can be used to sort the controlcyles by urgency.

The fields will be sorted in order of the "priority" which is defined for each field.

Example (mostly used in SUPPLIER-Production):

Priority 1: User-exit2 (Urgency)

Priority 2: Supply area

Priority 3: Part-number

Don’t forget to "Save" (四 Save User Data) the changes. 


\subsection{Kanban-correction}

If there goes something wrong during the status change of a Kanban-bin (e.g. The PO could not be created because this material number is blocked from another user) the bin color changes to "white with a red border" 15751 which signs a Kanban bin as "incorrect".

With the "Kanban-correction" these faulty or incorrect bins can be corrected. Also inadvertently done status changes can be undo.

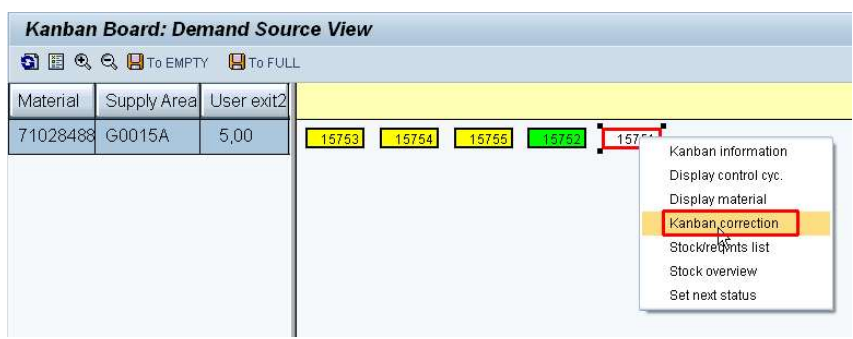

Right click on the bin which should be corrected and then choose "Kanban-correction"

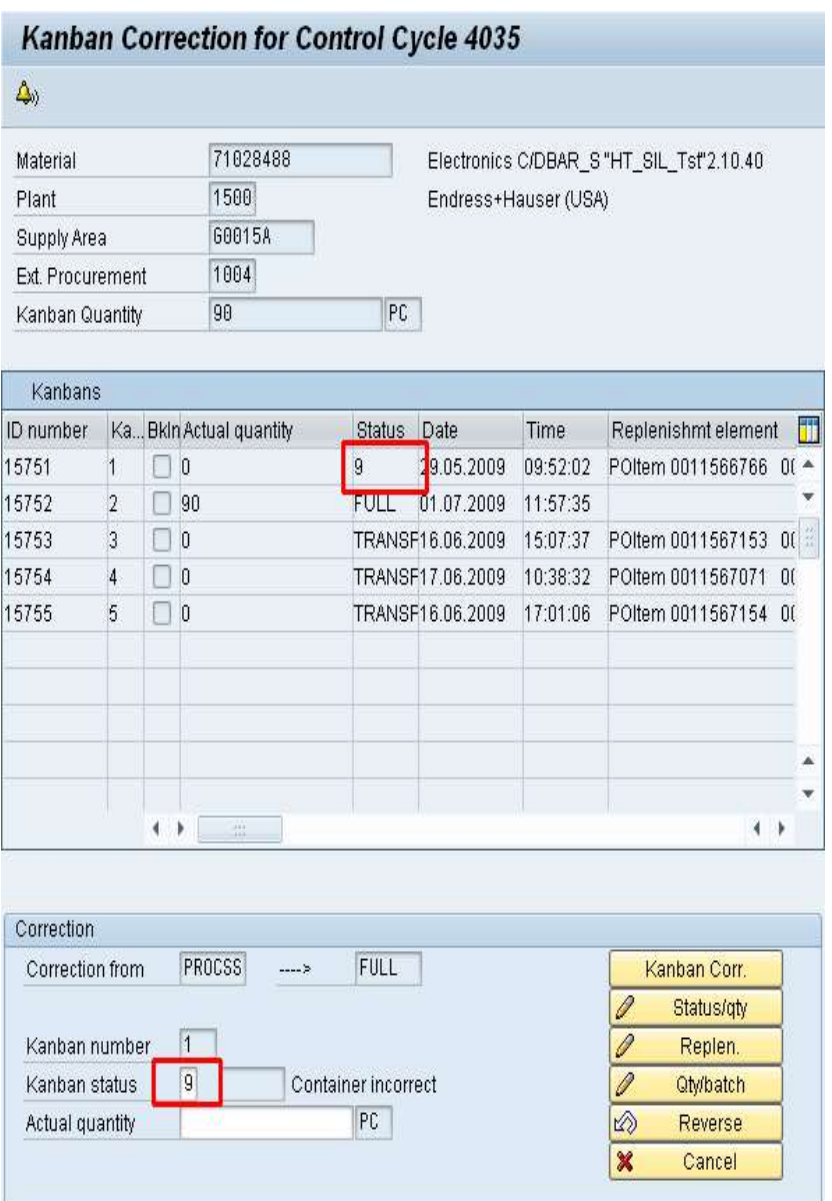

Doubleclick the line, of the bin, which should be corrected. Status "9" stands for "Container incorrect". To reverse another status change, choose the line to correct and doubleclick it.

Then the correction window appears underneath

To repeat an unsuccessful status change click the button "Kanban-correction".To set a specific status, choose the status in the field "Kanban-status" and click the button "Status/qty".

To undo a status change, only the button "Reverse" must be clicked. All background activities will be cancelled and the previous status will be set again.

After leaving the Kanban-correction all changes are saved automatically.

\section{Please note:}

This Kanban-correction can only be done by the Kanban-experts with special authorities.

If a Kanban status "PROCSS" has to be undo, SUPPLIER has to be informed because status PROCSS means: purchase order in CONSUMER and also Sales order in SUPPLIER is created. The PO will be deleted automatically but not the SO. SO SUPPLIER has to cancel the corresponding SO manually!

\subsection{Peaks in demands (project demands)}

A fundamental rule for any known future peak in demands caused by a big customer order (project) is an intensiv communication between consumer (CONSUMER) and supplier (SUPPLIER). As soon as SUPPLIER knows about these additional demands, they can take the necessary measures, together with the CONSUMER, 
to fulfill them. So the sooner SUPPLIER knows, the better it is. There are different possibilities what to do. Each of them will be described in detail:

- Increasing the number of bins

- Event-driven Kanbans

- Creating additional PO's manually besides the controlcycle

\subsubsection{Increasing the number of bins}

The first possibility is, to create additional bins in the affected controlcycle and then scan them empty. Afterwards these additional bins must be locked (see chapter Error! Reference source not found.), to avoid a repeated Empty-scanning. If a locked bin will be empty-scanned, the status changes to WAIT and the bin could be deleted again (see chapter 3.2.4).

Please note: This can all only be done if SUPPLIER has enough stock for these additional demands and has agreed to this procedure!

\subsubsection{Event-driven Kanban}

If there are part-numbers which there's more frequently the need of additional bins it would be worthwhile to create so called "Event-driven Kanban controlcycles". This kind of controlcycle allows adding very easy additional bins which will be filled only once and after the second empty scan they vanish again.

Event-driven controlcycle don't have any bins. If there's an additional demand, there can be activated any number of bins which will be used only once, to cover these additional demands.

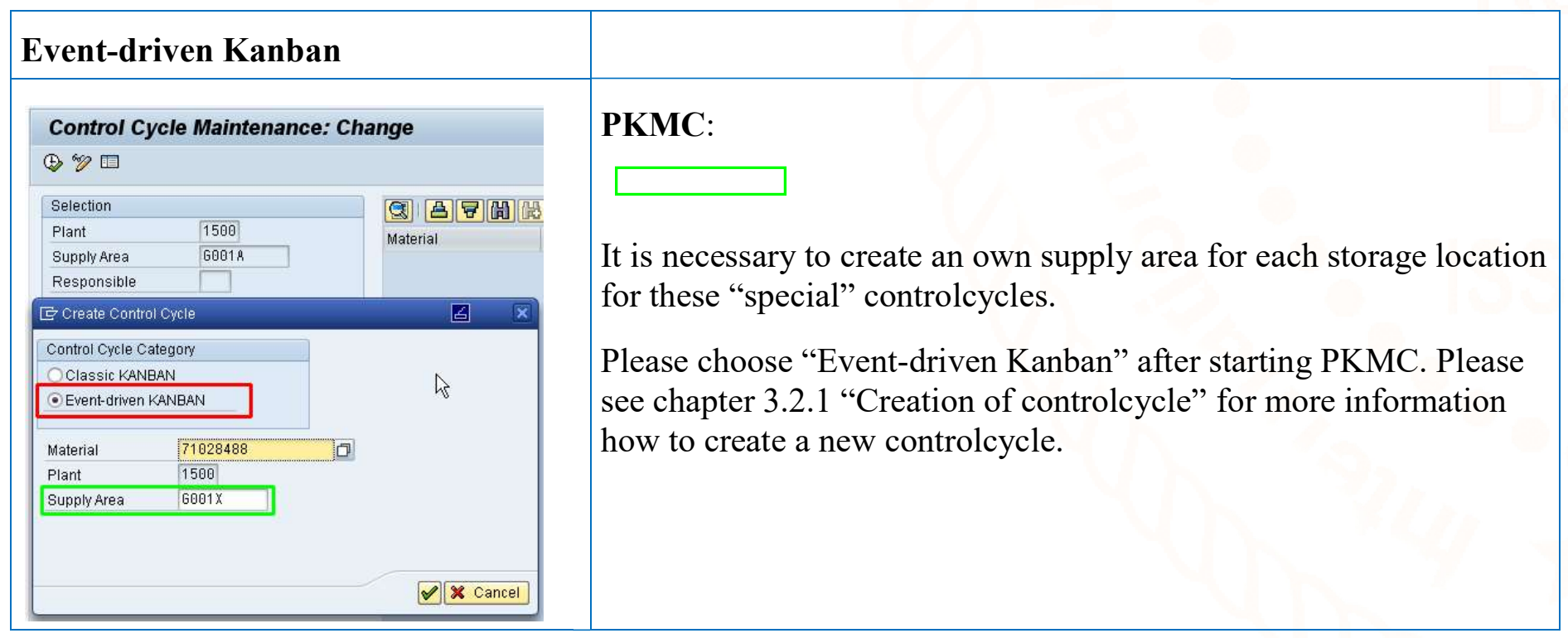




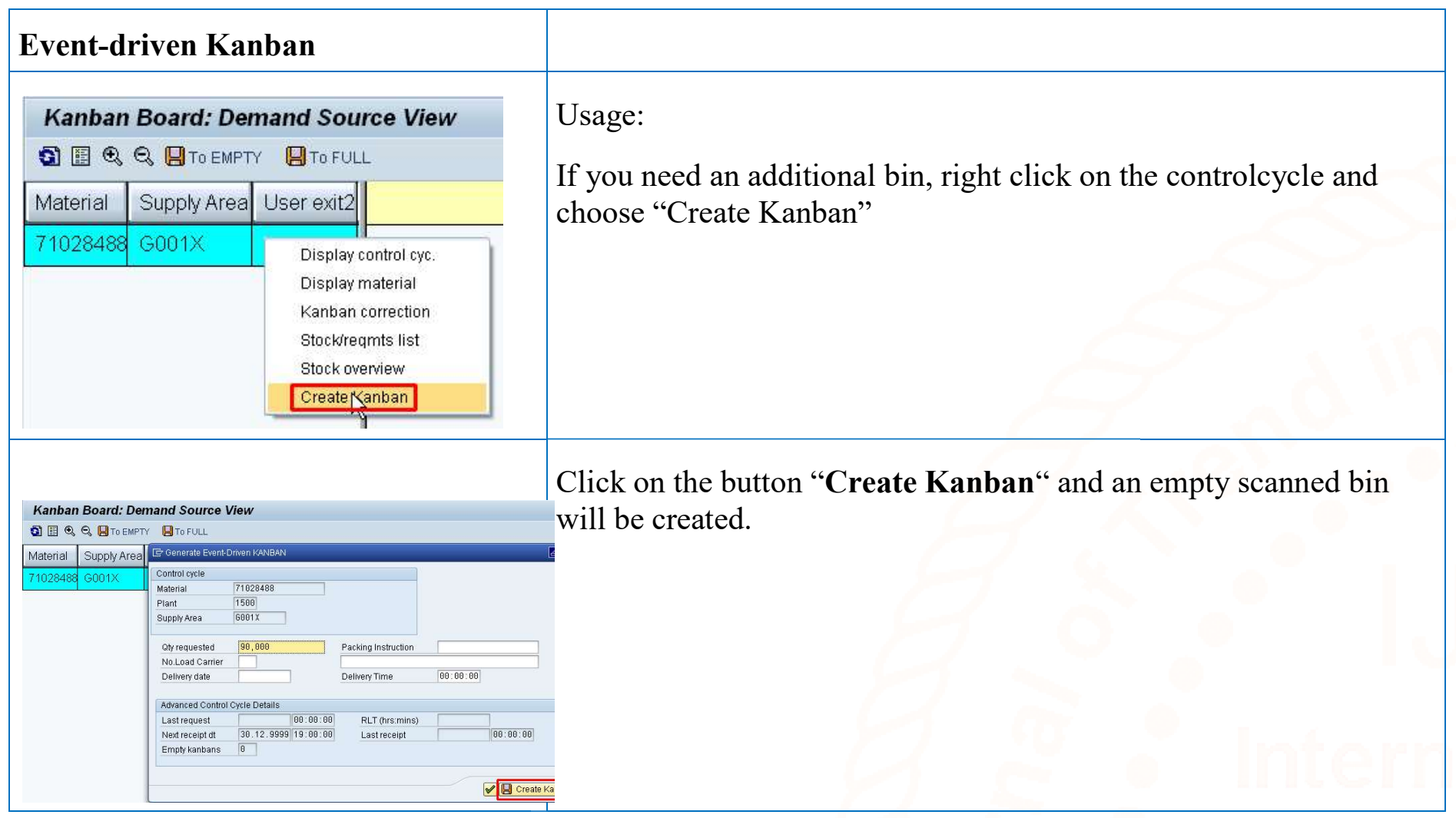

Please note: This also can only be done if SUPPLIER has enough stock for these additional demands and has agreed to this procedure!

\subsubsection{Creating additional PO's manually}

The third possibility is, to create additional PO's beside the normal CONSUMER-Kanban supply, which will be handled completely separated from this automatic process on both sides. Following steps have to be done:

- A "normal" PO (PO-type NB) has to be created manually with the additional quantity. Purchasing group mustn't be GK1 to GK9, to avoid the creation of a Kanban-Sales order in SUPPLIER.

- Order will be transferred via EOI to SUPPLIER and creates a "normal" SO for CONSUMER-supply.

- SO will be proceeded manually as any other SO for CONSUMER-supply. SUPPLIER takes the necessary measures to fulfill these additional demands.

- Material will be shipped as a normal CONSUMER-supply "without" Kanban-card because there's no corresponding Kanban-bin on the CONSUMER-side.

- Material must be received, stocked and consumed as a normal CONSUMER-supply material, completely besides the Kanban-stock in the CONSUMER-production.

Please note: This can only be done after detailed coordination and agreement about quantities and dates, between CONSUMER and SUPPLIER.

\subsection{Statistic evaluation}

\subsubsection{Evaluate Kanbans without status changes}

With the program,ZMZKAN08' "Kanban without status change" Kanbans can be found out, which the last status change has been done before $n$ hours. This means there must have been a problem which prevented any further status change. 


\section{KANBAN ohne Statuswechsel}

\section{(A) 四}

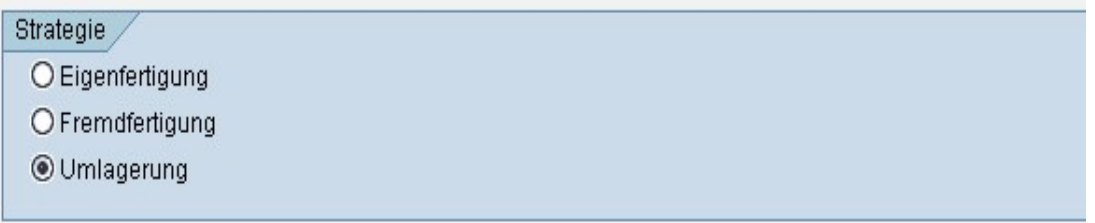

\begin{tabular}{|c|c|c|c|}
\hline Selektion & & \multirow[b]{4}{*}{ bis } & \multirow[b]{4}{*}{$\Leftrightarrow$} \\
\hline Werk & 0001 & & \\
\hline Umlagerung & 0003 & & \\
\hline Regelkreisnummer & & & \\
\hline Identnummer & & bis & $\Rightarrow$ \\
\hline ProdversorgBereich & $0047 a$ & bis & $\Rightarrow$ \\
\hline Kanbanstatus & 4 & & \\
\hline Lagernummer & 001 & & \\
\hline Statuswechsel wor $>n-$ Stunden & 48 & & \\
\hline
\end{tabular}

\section{KANBAN ohne Statuswechsel}

\begin{tabular}{|c|c|c|c|c|c|c|c|c|c|c|}
\hline 9 & 量冢屋 & 国罱 & 霸 & 哆 喝 & 㘣 & 四 & 囲 & & & \\
\hline Regel. & Material & IdentNr. & PrversBer. & r. Status | & Folge & Werk & Stunden & TB-Nr & TA-Nr & $=$ Zähler \\
\hline 34 & 71021404 & 156 & $0047 \mathrm{~A}$ & 4 & KAN3 & 0001 & 1658: $27: 21$ & 800631 & & 1 \\
\hline 34 & 71021404 & 157 & $0047 \mathrm{~A}$ & 4 & KAN3 & 0001 & $1658: 27: 20$ & 800630 & & 1 \\
\hline 37 & 71021412 & 163 & $0047 \mathrm{~A}$ & 4 & KAN3 & 0001 & 2010: $27: 19$ & 784329 & & 1 \\
\hline 49 & 52013823 & 191 & $0047 \mathrm{~A}$ & 4 & KAN3 & 0001 & $1624: 27: 39$ & 802659 & & 1 \\
\hline 50 & 52013781 & 192 & $0047 \mathrm{~A}$ & 4 & KAN3 & 0001 & 1968: $27: 2$ & 786388 & & 1 \\
\hline 50 & 52013781 & 193 & $0047 \mathrm{~A}$ & 4 & KAN3 & 0001 & 1818: $27: 8$ & 793438 & & 1 \\
\hline 52 & 52013788 & 197 & $0047 \mathrm{~A}$ & 4 & KAN3 & 0001 & 1718: $27: 38$ & 797974 & & 1 \\
\hline 52 & 52013788 & 198 & $0047 \mathrm{~A}$ & 4 & KAN3 & 0001 & $2126: 27: 13$ & 778731 & & 1 \\
\hline 57 & 52013786 & 211 & $0047 \mathrm{~A}$ & 4 & KAN3 & 0001 & $1628: 27: 24$ & 802543 & & 1 \\
\hline 57 & 52013786 & 212 & $0047 \mathrm{~A}$ & 4 & KAN3 & 0001 & $1626: 27: 26$ & 802655 & & 1 \\
\hline 434 & 012079-1001 & 1905 & $0047 \mathrm{~A}$ & 4 & KAN3 & 0001 & 1608: $27: 0$ & 803226 & & 1 \\
\hline 434 & $012079-1001$ & 1911 & $0047 \mathrm{~A}$ & 4 & KAN3 & 0001 & $1824: 26: 30$ & 792925 & & 1 \\
\hline 523 & $012079-0001$ & 2149 & $0047 \mathrm{~A}$ & 4 & KAN3 & 0001 & $1780: 25: 47$ & 794852 & & 1 \\
\hline 523 & $012079-0001$ & 2150 & $0047 \mathrm{~A}$ & 4 & KAN3 & 0001 & $1700: 26: 14$ & 799041 & & 1 \\
\hline 2487 & 71039827 & 8587 & $0047 \mathrm{~A}$ & 4 & KAN3 & 0001 & 1606: $23: 10$ & 803449 & & 1 \\
\hline 2279 & 71039858 & 7925 & $0047 \mathrm{~A}$ & 4 & KAN3 & 0001 & $2112: 24: 14$ & 779423 & 892914 & 1 \\
\hline 2279 & 71039858 & 7931 & $0047 \mathrm{~A}$ & 4 & KAN3 & 0001 & $2010: 26: 19$ & 784332 & 898229 & 1 \\
\hline 2279 & 71039858 & 7932 & $0047 \mathrm{~A}$ & 4 & KAN3 & 0001 & 2006: $27: 4$ & 784436 & 898345 & 1 \\
\hline 15 & 52017675 & 98 & $0047 \mathrm{~A}$ & 4 & KAN3 & 0001 & 1868: $27: 9$ & 791292 & 905622 & 1 \\
\hline 54 & $942421-1603$ & 2711 & $0047 \mathrm{~A}$ & 4 & KAN3 & 0001 & 1672: $27: 25$ & 800246 & 915366 & 1 \\
\hline 17 & 52023679 & 103 & $0047 \mathrm{~A}$ & 4 & KAN3 & 0001 & 1672: $27: 31$ & 800253 & 915456 & 1 \\
\hline 20 & 52017669 & 118 & $0047 \mathrm{~A}$ & 4 & KAN3 & 0001 & $1624: 27: 41$ & 802660 & 918075 & 1 \\
\hline 24 & 71021401 & 133 & $0047 \mathrm{~A}$ & 4 & KAN3 & 0001 & 1606: $26: 43$ & 803423 & 918812 & 1 \\
\hline 199 & 71007304 & 750 & $0047 \mathrm{~A}$ & 4 & KAN3 & 0001 & $1606: 26: 13$ & 803450 & 918813 & 1 \\
\hline 199 & 71007304 & 4966 & $0047 \mathrm{~A}$ & 4 & KAN3 & 0001 & 1606: $26: 11$ & 803452 & 918814 & 1 \\
\hline 25 & 71021402 & 139 & 0047A & 4 & KAN3 & 0001 & 1606: $26: 40$ & 803419 & 918823 & 1 \\
\hline & $71 n 314 n 1$ & & $\operatorname{n\cap A7\pi }$ & $A$ & I/Rniz & nnกs & 1EกE. วE. AE & $\mid \overline{\text { onวa31 }}$ & D1002A & \\
\hline
\end{tabular}

Currently we have the restriction that we can't evaluate max. 99 hours delay. That could be probably not enough to use this tool for the CONSUMER-Kanban.

\section{We are working on this issue!}

Anyway, this tool can for example be used to check if there are any Kanban's in the CONSUMER which are more than 4 hours on status EMPTY because normally each empty bin of an CONSUMER-Kanban Controlcycle must be set max. $2 \mathrm{~h}$ later to status PROCSS "Container in process" by a cyclic job which runs every two hours.

The created list shows all Kanbans at which the last status change was longer than $\mathbf{n}$ hours ago.

\section{4 Evaluation of Kanbans with MCQ.}

There exists another transaction which can be used for different analyses in the Kanban environment. It is called "MCQ."

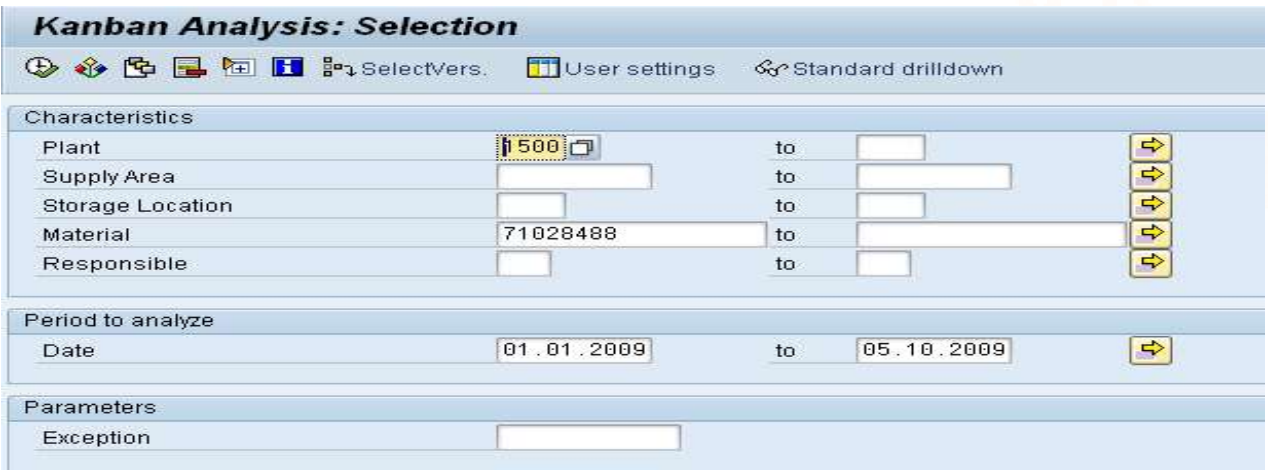

This is a SAP standard transaction with functions which are very similar to MC02. There can be selected plant specific data of controlcycles with different select options. 


\section{Appendix}

\subsection{SAP-authorities}

\begin{tabular}{|c|l|}
\hline \begin{tabular}{|l|} 
SAP-authorization \\
Kanban-normal
\end{tabular} & $\begin{array}{l}\text { 2Kanban, PK13n } \\
\text { PK12n, PKBC }\end{array}$ \\
\hline Kanban-extended & All Kanban-transactions \\
except PK05 and PK31 \\
\hline Kanban-extra & All Kanban-transactions \\
\hline
\end{tabular}

\subsection{PK-transactions}

\begin{tabular}{|c|c|}
\hline Transaction & Function \\
\hline PKMC & Controlcycle maintenance (Create/Change/View) \\
\hline PK05 & Supply area create, change and view \\
\hline PK05S & Quick: Supply area create, change and view \\
\hline PK10 & Mass-change Kanban-controlcycles \\
\hline PK1 1 & Kanban-Plant overview \\
\hline PK12n & Kanban-board Source view \\
\hline PK13n & Kanban-board demand view \\
\hline $\mathrm{PKBC}$ & Kanban-impulse (Full-/Empty-scan with Barcode) \\
\hline PK18 & Controlcycle- and Kanban-Evaluation \\
\hline MCQ. & Kanban-analysis \\
\hline PK31 & Kanban-correction \\
\hline zKanban & Kanban-Cockpit \\
\hline ZMZKAN02 & Evaluation: Kanban Status-changes \\
\hline ZMZKAN08 & Evaluation: Kanban without Status-changes \\
\hline ZMZKAN09 & $\begin{array}{l}\text { Supplier Kanban: Check Master data / Update Purchase } \\
\text { order }\end{array}$ \\
\hline
\end{tabular}


International Journal of Trend in Scientific Research and Development (IJTSRD) ISSN: 2456-6470

\begin{tabular}{|c|l|}
\hline Transaction & \multicolumn{1}{c|}{ Function } \\
\hline PK01 (obsolete) & Create controlcycle \\
\hline PK02 (obsolete) & Change controlcycle \\
\hline PK03 (obsolete) & View controlcycle \\
\hline
\end{tabular}

\subsection{Checklist for the changeover}

\begin{tabular}{|c|c|c|}
\hline Changeover to CONSUMER-Kanban & & $\mathbf{O K}$ \\
\hline Changings in material master & MM02 & \\
\hline $\begin{array}{l}\text { Purchasing Group to } \mathbf{K}^{*} \\
\text { USA: GK1 to GK9 } \\
\text { China: SK1 to SK9 } \\
\text { India: AK1 to AK9 }\end{array}$ & MM02, purchasing & \\
\hline $\begin{array}{l}\text { Goods receipt processing time (Average transport time from } \\
\text { SUPPLIER to CONSUMER + internal handling time } \\
\text { CONSUMER) } \\
\text { USA: " } 4 \text { " workdays } \\
\text { China: "7" workdays } \\
\text { India: tbd }\end{array}$ & MM02, purchasing & \\
\hline MRP-type "ZKK" & MM02; MRP 1 & \\
\hline $\begin{array}{l}\text { MRP-controller to *K* } \\
\text { USA: GK1 to GK9 } \\
\text { China: SK1 to SK9 } \\
\text { India: AK1 to AK9 }\end{array}$ & MM02; MRP 1 & \\
\hline Fixed lot size or min. and max. Lot size same than bin quantity & MM02; MRP 1 & \\
\hline Rounding value same than bin quantity & MM02; MRP 1 & \\
\hline Remove Reorderpoint & MM02; MRP 1 & \\
\hline $\begin{array}{l}\text { Planned delivery time to"3" days (Internal handling time } \\
\text { SUPPLIER + Time shift between CONSUMER and } \\
\text { SUPPLIER (Normally } \mathbf{3 - 5} \text { days)) }\end{array}$ & MM02; MRP 2 & \\
\hline SchedMargin key: Must be "R" & MM02; MRP 2 & \\
\hline Safety time indicator " 2 " & MM02; MRP 2 & \\
\hline Safety time $=$ Safety time from Kanban-calculation & MM02; MRP 2 & \\
\hline Remove safety stock & MM02; MRP 2 & \\
\hline
\end{tabular}


Storage location MRP indicator "1" (necessary for Controlcycle-creation)

All other fields must be empty!

Storage bin: Coordinate / place where the material physically is stored (shelve position). This information will be printed on the Kanban card.

Changings in info record

Planned delivery time $=$ same than in material master

Purchasing group $=$ same than in material master

Standard quantity $=$ Quantity per bin

Minimum quantity $=$ Quantity per bin

Changings in source list

Fixed source of supply: Must be checked $\sqrt{ }$

Usage in MRP: Must be "1"

Kanban preparations

Create supply area

Create controlcycle

Empty the storage location MRP indicator (only necessary for Controlcycle-creation)

Prepare Kanban shelve / label storage position

Transfer existing stock to Kanban-shelve and repack into Kanban bins

Create the transition Kanban cards and label the Kanban bins
Kanban storage location

MM02; MRP 4 /

Kanban storage

location

MM02; Plant data

/stor.1 for Kanban

storage location

ME12

Purch. Organization

Data 1

Purch. Organization

Data 1

Purch. Organization

Data 1

Purch. Organization

Data 1

ME01

Source list

Source list

PK05

PKMC

MM02; MRP 4 /

Kanban storage

location

Production

Production

Excel tool 
6.4 Containers / bins

\begin{tabular}{|l|l|l|}
\hline \multicolumn{1}{|c|}{ Matno. } & \multicolumn{1}{|c|}{ Short description } & \multicolumn{1}{|c|}{ Dimensions } \\
\hline $\mathbf{7 1 0 8 3 8 0 5}$ & Carton "B3" & $300 \times 200 \times 120$ \\
\hline $\mathbf{7 1 0 8 3 8 0 6}$ & Carton "B4" & $400 \times 300 \times 120$ \\
\hline $\mathbf{7 1 0 8 3 8 0 7}$ & Carton "B5" & $400 \times 300 \times 220$ \\
\hline $\mathbf{7 1 0 8 3 8 1 0}$ & Carton "BA" & $600 \times 400 \times 120$ \\
\hline $\mathbf{7 1 0 8 3 8 0 8}$ & Carton "B6" & $600 \times 400 \times 220$ \\
\hline $\mathbf{7 1 0 8 3 8 0 9}$ & Carton "B7" & $600 \times 400 \times 320$ \\
\hline $\mathbf{7 1 0 3 4 6 5 4}$ & Half pallet & $800 \times 600$ \\
\hline $\mathbf{7 1 0 3 4 6 4 8}$ & Full pallet & $1200 \times 800$ \\
\hline
\end{tabular}

\section{Conclusion:}

This proves that Kanban is an effective inventory management system which helps an organisation to achive the best results in the following key result ares of operation of any plant. JIT is implemented thru the Kanban way:

1) Only required / consumed material is getting ordered so unnecessary stocks don't get piled up.

2) Vendor is getting sufficient lead time to supply the right material on right time.

3) Right quantity \& right quality of material is always on the shelf for production.

4) Even in unpredictable consumption items the material stocks are reviewed \& getting replenished after consumption only.

5) Slow moving \& non moving consumption material is not getting ordered \& hence the stocks are controlled.

6) There is no last minute rush happening $\&$ despatches to customers are happening in time as per the promise date.

7) Kanban helps organisation to improve the inventory turn which is a one of the most important key result area for any organisations success.

8) Since the right material \& right qty is received in the plant, it saves huge storage space which can be utilized for productive work.

\section{Refernces:}

1) Kanban - Wikipedia, the free encyclopedia.

2) Various literature on www.google.co.in 